\title{
MALDI-TOF mass spectrometry: a new tool for rapid identification of cercariae (Trematoda, Digenea)
}

\author{
Antoine Huguenin ${ }^{1,2, *}$, Jérôme Depaquit ${ }^{1,2,3}$, Isabelle Villena ${ }^{1,2}$, and Hubert Ferté ${ }^{1,2,3}$ \\ ${ }^{1}$ EA 7510, ESCAPE, Laboratoire de Parasitologie-Mycologie, Université de Reims Champagne-Ardenne, 51 rue Cognacq Jay, 51092 \\ Reims CEDEX, France \\ ${ }^{2}$ Laboratoire de Parasitologie Mycologie, CHU de Reims, Hôpital Maison Blanche, 45 rue Cognacq Jay, 51092 Reims CEDEX, France \\ ${ }^{3}$ USC ANSES Transmission vectorielle et épidémiosurveillance de maladies parasitaires (VECPAR), Reims, France
}

Received 23 November 2018, Accepted 20 February 2019, Published online 6 March 2019

\begin{abstract}
Identification of cercariae was long based on morphological and morphometric features, but these approaches remain difficult to implement and require skills that have now become rare. Molecular tools have become the reference even though they remain relatively time-consuming and expensive. We propose a new approach for the identification of cercariae using MALDI-TOF mass spectrometry. Snails of different genera (Radix, Lymnaea, Stagnicola, Planorbis, and Anisus) were collected in the field to perform emitting tests in the laboratory. The cercariae they emitted (Trichobilharzia anseri, Diplostomum pseudospathaceum, Alaria alata, Echinostoma revolutum, Petasiger phalacrocoracis, Tylodelphys sp., Australapatemon sp., Cotylurus sp., Posthodiplostomum sp., Parastrigea sp., Echinoparyphium sp. and Plagiorchis sp.) were characterized by sequencing the D2, ITS2 and ITS1 domains of rDNA, and by amplification using specific Alaria alata primers. A sample of each specimen, either fresh or stored in ethanol, was subjected to a simple preparation protocol for MALDI-TOF analysis. The main spectral profiles were analyzed by Hierarchical Clustering Analysis. Likewise, the haplotypes were analyzed using the maximum likelihood method. Analytical performance and the log-score value (LSV) cut-off for species identification were then assessed by blind testing. The clusters obtained by both techniques were congruent, allowing identification at a species level. MALDI-TOF enables identification at an LSV cut-off of 1.7 without false-positives; however, it requires more data on closely related species. The development of a "high throughput" identification system for all types of cercariae would be of considerable interest in epidemiological surveys of trematode infections.
\end{abstract}

Key words: MALDI-TOF, Trematoda, Furcocercariae, identification, High-throughput identification, snails.

Résumé - La spectrométrie de masse MALDI-TOF, nouvel outil pour l'identification rapide des cercaires (Trematoda, Digenea). L'identification des cercaires a longtemps été basée sur des caractéristiques morphologiques et morphométriques, mais ces approches restent difficiles à utiliser et nécessitent des compétences devenues rares de nos jours. Les outils moléculaires sont devenus la référence mais restent relativement coûteux en temps et en argent. Nous proposons une nouvelle approche pour l'identification des cercaires à l'aide de la spectrométrie de masse MALDI-TOF. Des mollusques de différents genres (Radix, Lymnaea, Stagnicola, Planorbis, Anisus) récoltés en milieu naturel ont été soumis à des tests d'émission au laboratoire. Les cercaires émises (Trichobilharzia anseri, Diplostomum pseudospathaceum, Alaria alata, Echinostoma revolutum, Petasiger phalacrocoracis, Tylodelphys sp., Australapatemon sp., Cotylurus sp., Posthodiplostomum sp., Parastrigea sp., Echinoparyphium sp. et Plagiorchis sp.) ont été caractérisées par séquençage des domaines D2, ITS2 et ITS1 de l'ADNr et par l'amplification d'amorces spécifiques d'Alaria alata. Un échantillon de chaque échantillon, frais ou stocké dans l'éthanol, a été soumis à un protocole de préparation simple pour l'analyse MALDI-TOF. Les spectres de référence obtenus (Main Spectra Profiles : MSP) ont été analysés par HCA (Hierarchical Clustering Analysis). Parallèlement, les haplotypes ont été analysés en Maximum de vraisemblance. La performance analytique et le seuil des valeurs de log-score (LSV) pour l'identification des espèces ont ensuite été évalués par des tests à l'aveugle. Les groupes obtenus par les deux techniques étaient congruents, permettant une identification à un niveau spécifique. Une valeur seuil de LSV à 1,7 a permis l'identification de cercaires en MALDI-TOF sans faux-positif, mais davantage de données sur les espèces étroitement apparentées sont nécessaires pour valider ce seuil. La mise au point d'un système d'identification "à haut débit" pour tous les types de cercaires présenterait un intérêt majeur pour les enquêtes épidémiologiques sur les trématodoses.

*Corresponding author: ahuguenin@chu-reims. fr

This is an Open Access article distributed under the terms of the Creative Commons Attribution License (http://creativecommons.org/licenses/by/4.0), which permits unrestricted use, distribution, and reproduction in any medium, provided the original work is properly cited. 


\section{Introduction}

In the life cycle of Trematoda, the first intermediate host is a mollusc, usually an aquatic snail. This host releases cercariae into the environment. Cercariae are free living mobile larval stages that must locate a suitable second definitive or intermediate host $[17,33]$. The study of cercariae is therefore essential to understand the epidemiology of Trematoda and their ecological relationships with their hosts. Trematodes are one of the most important parasites in medical and veterinary parasitology. For example, the furcocercariae of Schistosoma are the causal agent of schistosomiasis which affects more than 230 million people worldwide [6], and the Fasciola hepatica fluke is a parasite of high importance in veterinary medicine [26].

Traditional identification of cercariae is based on their natural environment (fresh or saline water), the species of emitting molluscs, and their morphological features (presence of eye spots, type of tail, position of suckers, osmotic regulation system, and distribution of sensory papilla). However, this approach presents several limitations. The morphology of different species within the same genus is very similar at the cercarial stage, which renders species identification particularly challenging. The required expertise for identification is long to acquire and it is the prerogative of a small number of specialists whose number is in constant decline. Particular technical skills are also required for several coloration techniques such as silver-impregnation and borax-carmine staining [7, 11].

Molecular biology is becoming the gold standard for the identification of Trematodes at larval stages. Use of the D2 domain of the 28S subunit and the internal transcribed spacers (ITS2 and ITS1) of ribosomal DNA (rDNA), or the cytochrome $\mathrm{C}$ oxidase I (COI) gene of mitochondrial DNA has made it possible to refine the taxonomy of Trematodes [2]. Molecular techniques enable researchers to differentiate cryptic species that are morphologically similar at the larval or adult stages $[14,20]$. These molecular tools have great discriminatory power, but (i) they are still sometimes technically challenging and remain time- and resource-consuming, and (ii) GenBank does not include sufficient sequences to allow for strong species identification, especially sequences obtained from adults (except for the most common parasites of human and veterinary importance).

Matrix-Assisted Laser Desorption/Ionization Time-OfFlight Mass Spectrometry (MALDI-TOF MS) is now a widely used technique for easy, rapid, and reliable routine identification of bacteria and yeasts [5, 31, 34]. This technique is based on laser ionization of sample proteins after co-crystallization with MALDI-matrix and comparison of the obtained mass spectra with a database of reference spectra [5]. MALDI-TOF MS is currently under development for the study of protozoa with potential use for the identification of Leishmania [22], Plasmodium [23] and trypanosomatids [1]. Few applications, however, have been proposed in the field of helminthology. MALDI-TOF has recently proved its effectiveness for the rapid identification of Trichinella at the genus and species levels, with a high degree of confidence [27]. In the case of Trematodes, MALDI-TOF MS has been used to find biomarkers for schistosomiasis in mice sera, allowing for very early detection of the infection in this animal model [18].
We propose the use of MALDI-TOF MS as a rapid and inexpensive method for high-throughput identification of cercariae.

The goal of the present study was to design a simple protocol for acquiring MALDI-TOF spectra of cercariae freshly emitted from snails. The discriminatory power of this technique was then investigated and formed a preliminary spectral database especially targeting the furcocercariae of diplostomoids. The analytical performance of this technique was also evaluated by performing blind validation. Finally, we studied the effect of storage in ethanol on cercariae identification.

\section{Materials and methods \\ Cercaria and snail collection}

Snails from four different areas were collected: the first one, regularly prospected during an epidemiological survey of the transmission of Alaria alata, is located in the center of France [(National Domain of Chambord (DNC): $48^{\circ} 35^{\prime} \mathrm{N} 1^{\circ} 55^{\prime} \mathrm{E}$ )]; the second is Der-Chantecoq lake (DR) in North-Eastern France $\left(48^{\circ} 35^{\prime} \mathrm{N} 4^{\circ} 45^{\prime} \mathrm{E}\right)$, the third was investigated in the context of human cercarial dermatitis from a recreational pond used for swimming [Zebulle Park/Chevenon (ZE) $\left(46^{\circ} 91^{\prime} \mathrm{N} 3^{\circ} 22^{\prime} \mathrm{E}\right)$ ], and the fourth is in a landscape of meadows in the locality of Jouaignes (JO) $\left(49^{\circ} 30^{\prime} \mathrm{N} 3^{\circ} 53^{\prime} \mathrm{E}\right)$.

Snails were collected by hand from April 2017 to June 2018. They were collected once in all areas, except for the DNC area where the collection was performed monthly from spring to summer.

Collections were pooled in the laboratory and cercarial emergence was stimulated by lighting for $30 \mathrm{~min}$ to $2 \mathrm{~h}$. Snails from positive batches were individualized for a second assay and preliminary screening of cercariae was performed using morphological features as proposed by Combes et al. [7] and Faltýnková et al. [10, 11]. Identification of snails was performed at the genus level according to Glöer and Meier-Brook [15]. Taking into account the fact that snails usually emitted one kind of cercariae, and after checking under a stereomicroscope, some of the cercariae were processed for MALDI-TOF, whereas others were preserved in 95\% ethanol for molecular analysis. Some samples from the foot of most positive snails were also collected. DNA extraction was performed using a QIAamp DNA mini kit (Qiagen, Germany), following the manufacturer's instructions.

In order to achieve molecular identification of the cercariae, we used the primers designed by Mollaret et al. [28] to amplify (i) the D2 domain of rDNA: C2'b (5'-GAAAAGTACTTTGRARAGAGA-3') and D2 (5'-TCCGTGTTTCAAGACGGG$3^{\prime}$ ); and those previously used by Dvorák et al. [9], to amplify (ii) the second internal transcribed spacer ITS2 (ITS3Trem 5'-GCG TCG ATG AAG AGT GCA GC-3' and ITS4Trem $5^{\prime}$-TCC TCC GCT TAT TGA TAT GC-3'), and (iii) the ITS1 (ITS2Trem, 5'-GCT GCA CTC TTC ATC GAC GC-3' and ITS5Trem, 5'-GGA AGT AAA AGT CGT AAC AAG G-3'). Furthermore, specific Alaria alata primers [ALAITS1 (5'-GGC TTG GGA GTA GGT TCC TG-3 ${ }^{\prime}$ ) and ALAITS2b (5'-GGT ATG TGT TGG CTG CTA GA-3')] were used to perform rapid 
identification of all cercariae exhibiting forked tails (LF/FO) according to Portier et al. [32].

Two snail's mitochondrial markers were amplified with the primers and in the conditions given by Jørgensen et al. [19]: large subunit $16 \mathrm{~S}$ with $16 \mathrm{Sar}-\mathrm{L} / 16 \mathrm{Sbr}-\mathrm{H}$ (5'-CGC CTG TTT ATC AAA AAC AT- $3^{\prime} / 5^{\prime}-\mathrm{CCG}$ GTC TGA ACT CAG ATC ACGT-3'), and COI with ASMIT1/ASMIT2 (5'-TTT TTG GGC ATC CTG AGG TTT AT- $3^{\prime} / 5^{\prime}$-TAA AGA AAG AAC ATA ATG AAA ATG-3'). PCR products were directly sequenced in both directions with the primers used for DNA amplification (Genoscreen, France). Sequence alignments were performed by ClustalW in BioEdit [16].

Sequence homology was evaluated by nucleotide BLAST requests (https://blast.ncbi.nlm.nih.gov/Blast.cgi). A lack of homology was considered for values lower than $97 \%$.

The evolutionary history was inferred by using the maximum likelihood method. The best evolution model (General Time Reversible model; GTR) with invariant sites was selected based on Akaike's Information Criterion (AIC) and Bayesian Information Criterion (BIC) using MEGA7 built-in function [21].

Initial tree(s) for the heuristic search were obtained automatically by applying the Neighbor-Join and BioNJ algorithms to a matrix of pairwise distances estimated using the Maximum Composite Likelihood (MCL) approach, and then selecting the topology with superior log likelihood value. Internal node support was assessed by a bootstrap test over 500 replicates. All positions containing gaps and missing data were eliminated. All evolutionary analyses were conducted in MEGA7.

\section{MALDI-TOF MS Spectral acquisition}

To achieve MALDI-TOF spectral acquisition, $2-5 \mu \mathrm{L}$ of water containing freshly emerged cercariae was directly spotted to the MALDI target or centrifuged at $4000 \mathrm{rpm}$ for $3 \mathrm{~min}$. After centrifugation, the pellet was washed with distilled water and $5 \mu \mathrm{L}$ was spotted onto the MALDI target plate (Bruker Daltonik GmbH, Bremen, Germany). Each sample was deposited in at least four replicates. After drying at room temperature, the samples were covered with $1 \mu \mathrm{L}$ of $70 \%$ formic acid. After complete drying, $1 \mu \mathrm{L}$ of matrix ( $\alpha$-cyano-hydroxy-cinnamic acid in solution with $2.5 \%$ trifluoroacetic acid and $50 \%$ acetonitrile in water, Bruker Daltonik) was added to each spot. The target was then air-dried at room temperature. MALDI-TOF spectrum acquisition was performed using a Microflex LT mass spectrometer controlled by FlexControl software (Bruker Daltonik) with detection of positive ions on a range of 2000 $20,000 \mathrm{~m} / \mathrm{z}$ (mass to charge ratio). Each spectrum was acquired from 240 laser shots on random regions of the spot using autoexecute mode. Instrument calibration was verified using the Bacterial Test Standard (Bruker Daltonik). Spectra were processed using the FlexAnalysis and MALDI-Biotyper v3.4 software suite (Bruker Daltonik). High quality spectra for each sample were selected to create reference spectra (Main Spectrum Profile: MSP) using the default Bruker Method, which were added to the in-house database. Hierarchical cluster analysis (MSP dendrogram) was performed on the newly created MSP using MALDI-Biotyper Compass Explorer v4.1 software, and a distance matrix was calculated using the correlation method and clustered with the Ward algorithm.

\section{Database validation and LSV cut-off determination}

The newly created MSP database was evaluated by means of a blind test performed with new specimens from the DR lake. These new specimens were also deposited in four replicates and each spot was acquired 12 times. The log-score value (LSV) calculated by the Bruker MALDI-Biotyper was then used to evaluate the reliability of species identification based on the similarity between the reference MSP and newly acquired spectra. The cut-off for LSV was determined on the basis of molecular identification using a receptor-operated-channel curve (ROC curve) calculated by logistic regression (SAS 9.4, Grégy-sur-Yerres, France).

\section{Evaluation of the effect of storage in ethanol}

In a first step, the specimens of the validation set stored in $80 \%$ ethanol were re-analyzed by MALDI-TOF 3 months (91 days) later, using the same parameters.

In a second step, specimens preserved in ethanol over a period ranging from 1 to 14 months were analyzed by MALDI-TOF. In order to evaluate the effect of ethanol fixation, some specimens were fixed in ethanol immediately after emission and analyzed by MALDI-TOF MS the same day. Differences between true positive rates and LSVs were analyzed using Chi-Square and ANOVA tests (SAS 9.4, Grégy-sur-Yerres, France).

\section{Results}

A total of 2786 snails were tested for cercarial emission and only a few of them, belonging to the Lymnaeidae (Radix, Lymnaea and Stagnicola), and Planorbidae (Planorbis and Anisus) were positive. The number of the snails tested for each site and the labels of samples used for analysis are reported in the Table 1.

According to the morphological type of emitted cercariae and their origin, some snails were used to evaluate identification by the MALDI-TOF approach versus characterization by molecular biology: one Radix was positive with ocellated pigmented furcocercariae (FO), three with furcocercariae with or without eye spots (LF), and two with cercariae of Echinostomatidae (EC); five Lymnaea stagnalis, three positive with LF, two with xiphidiocercariae (XI); 10 Stagnicola sp., eight positive with LF and two with EC; three Anisus sp. with LF; 38 Planorbis sp., 36 with LF, and two with Echinostomatidae (Table 2).

Twelve taxa were identified according to the domains used (D2, ITS1 et ITS2) and after comparison of their percentage of homology with sequences deposited in GenBank: FO: Trichobilharzia anseri; LF: Diplostomum pseudospathaceum, Tylodelphys sp., Australapatemon sp., Cotylurus sp., Posthodiplostomum sp., Parastrigea sp., Alaria alata; EC: Echinostoma revolutum, Petasiger phalacrocoracis, Echinoparyphium sp.; XI (Plagiorchis sp.) (Table 3). 
Table 1. Geographic origin of snails.

\begin{tabular}{|c|c|c|c|c|c|}
\hline Site & $\begin{array}{l}\text { Identification of } \\
\text { snails }\end{array}$ & $\begin{array}{l}\text { Number } \\
\text { analysed }\end{array}$ & $\begin{array}{c}\text { Prevalence } \\
(\%)\end{array}$ & $\begin{array}{l}\text { Positive } \\
\text { snails }\end{array}$ & Reference of positive snails \\
\hline \multirow[t]{2}{*}{$\begin{array}{l}\text { Der-Chantecocq } \\
\text { lake (DR) }\end{array}$} & $\begin{array}{l}\text { Lymnaea } \\
\text { stagnalis }\end{array}$ & 196 & 2.55 & 5 & DRLF1; DRLF3; DRLF4; DRXI2; DRXI3 \\
\hline & Radix sp. & 104 & 2.9 & 3 & DRLFO1; DREC1; DREC2 \\
\hline \multirow[t]{3}{*}{$\begin{array}{l}\text { National Domain of } \\
\text { Chambord (DNC) }\end{array}$} & Planorbis sp. & 1771 & 2.15 & 38 & $\begin{array}{l}\text { DCLF37; DCLF39-DCLF42; DCLF44;DCLF45; } \\
\text { DCLF48; DCLF53;DCLF54 } \\
\text { DCLF57; DCLF59; DCLF61; DCLF64;DCLF68; } \\
\text { DCLF71; DCLF72; DCLF75; DCLF76 } \\
\text { DCLF78; DCLF79; DCLF80; DCLF82; DCLF86; } \\
\text { DCLF92 to DCLF103; ECDC16; ECDC26 }\end{array}$ \\
\hline & Stagnicola sp. & 278 & 1.8 & 5 & DCLF43; DCLF88; DCLF89; DCLF90; DCLF91 \\
\hline & Anisus sp. & 144 & 2.08 & 3 & DCLF73; DCLF74; DCL77 \\
\hline $\begin{array}{l}\text { Zebulle Park } \\
\text { Chevenon (ZE) }\end{array}$ & Radix sp. & 248 & 1.2 & 3 & ZELF1; ZELF2; ZELF3 \\
\hline Jouaignes (JO) & Stagnicola sp. & 45 & 11.1 & 5 & JOLF1; JOLF2; JOEC1. JOEC2; JOEC3 \\
\hline
\end{tabular}

Furcocercariae identified as Cotylurus sp. were detected in Stagnicola palustris from different closed ponds of the National Domain of Chambord. Alaria alata can use one of two intermediate hosts collected the same day in the same ponds: Planorbis planorbis (e.g., DCLF57/59/61/64) or Anisus sp. (DCLF73/ DCLF74/DCLF77). Furcocercariae of Australapatemon sp. were observed in two species of snails from two distant sites (LFJO1/LFJO2 from Stagnicola palustris and LFDC42/ LFDC48/LFDCLFDC84/LFDC86 from Planorbis planorbis).

Consistent and reproducible MALDI-TOF MS spectra were acquired from all the specimens, except for LFDC96 (Parastrigea sp.) with peaks of high intensity between 2 and $20 \mathrm{kDa}$. All the 12 taxa from which spectra were acquired displayed different peak patterns (Fig. 1). Spectra were tested against the Bruker Taxonomy MSP library, providing no bacterial or fungal identification with log-score values $>1.5$.

The results of MSP cluster analysis are shown in Figure 2A. Specimens of the same species were grouped together in clusters clearly separated from other species, with low intra-species heterogeneity. Furcocercariae with forked tails without pigmented eye spots were particularly distant from the other cercariae. The classification is consistent when compared to that based on molecular data inferred using the maximum likelihood method (Fig. 2B).

The MSP database constructed with 10 species (20 MSP) was blind-tested against spectra acquired from 22 samples of freshly emitted cercariae representing five species. Among them, three species were present in the database (Alaria alata $n=15$ / 22, Australapatemon sp. $n=1 / 22$, and Echinoparyphium sp. $n=1 / 22$ ). Among the 1056 acquisitions, 264 spectra (25\%) were flat-line spectra and were therefore not included in the analysis. In the 792 remaining spectra, 648 were acquired from species present in the database. Among them, only 147/648 (22.68\%) reached the Bruker recommended cut-off LSV of 2.0 for species level identification. However, an LSV of 1.7 sufficient for genus identification was obtained in $443 / 648$ spectra $(68.36 \%)$. In order to evaluate the best LSV cut-off for cercariae identification, a logistic regression model, based on concordance of MALDI-TOF and molecular data was then built. The ROC curve is shown in Figure 3. The area under the curve of the model was 0.9501 (95\% Wald confidence limits: $0.9357-$ 0.9644). Choosing an LSV threshold of 1.7 enabled us to obtain specificity of $100 \%$, with sensitivity of $81.7 \%$ (Fig. 3). No false identification was reported using 1.7 and 2.0 cut-off LSV, even for the taxa which were not present in the database, 108 spectra of Cotylurus sp. (LFDC43, LFDC88, LFDC89, LFDC90, LFDC91) and 36 spectra of the Posthodiplostomum sp. (LFDC83). The database was then updated to include Cotylurus sp. with MSPs generated from LFDC89 and LFDC90. This new version yielded good performance for species identification of Cotylurus sp. (78 correct identification among the 78/108 spectra attaining the LSV cut-off of 1.7). This updated database had similar performances with 521/792 spectra reaching the 1.7 cut-off $(65.78 \%)$, with $100 \%$ correct identifications.

Retrospectively, we did not observe any differences in terms of spectral profile between cercariae of the same species from one year to the next. For example, spectra of Alaria alata isolated at Chambord (LFDC41/44/45/50/51/52/53/54) in 2017 did not differ from those isolated in 2018 (LFDC57-LFDC72). We also did not observe any difference between cercariae of the same species isolated from different sites: for example, Australapatemon sp. spectra from specimen LFJO1-LFJO2 isolated in the JO site were not different from those isolated from Chambord (LFDC42, LFDC48, LFDC84, LFDC86).

We observed in one case, re-emission of the same cercariae (LFDC88: Cotylurus sp.) by the same mollusc (DCLF88) 90 days later. There was no difference in the spectral profile between the first and the second emission.

In order to assess the potential use of this new tool, we evaluated the effect of ethanol conservation on analytical performance. We compared the LSV and the rate of true positives between freshly emitted cercariae in the blind validation specimens and cercariae of the same emission preserved over 3 months in 80\% ethanol. Among the 1114 spectra acquired, 553 (49.64\%) were flatline spectra. In the 561 spectra analyzed using the updated database, 183 reached the cut-off LSV (32.62\% vs $65.78 \%$ without ethanol $p<0.0001)$. The mean LSV was 1.80 (Median: 1.93; Min: 0.13; Max: 2.77) for freshly emitted cercariae versus 1.62 (Median: 1.71; Min: 0.43; Max: 2.48; $p<0.0001)$ for cercariae preserved in ethanol. Interestingly, 
Table 2. Molecular identification of processed cercariae.

Cercarial reference Cercarial identification Genbank accession numbers obtained in the present study (in red) and homologies with those extracted from Genbank (in black). In grey, no molecular identification.

\begin{tabular}{|c|c|c|c|c|}
\hline & & & \\
\hline & & D2 & ITS2 & ITS1 \\
\hline FODR1 & Trichobilharzia anseri & $\begin{array}{l}\text { MK168701 100\% with } \\
\text { FJ93861 }\end{array}$ & $\begin{array}{l}\text { MK168683 100\% with } \\
\text { FJ469785 }\end{array}$ & $\begin{array}{l}\text { MK168665 99\% with } \\
\text { FJ469785 }\end{array}$ \\
\hline LFDR1 & $\begin{array}{l}\text { Diplostomum } \\
\text { pseudospathaceum }\end{array}$ & $\begin{array}{l}\text { MK168711 99\% with } \\
\text { KR269766 }\end{array}$ & $\begin{array}{l}\text { MK168684 100\% with } \\
\text { KR269766 }\end{array}$ & $\begin{array}{l}\text { MK168668 99\% with } \\
\text { KR269766 }\end{array}$ \\
\hline LFDR3 & & $\begin{array}{l}\text { MK168712 99\% with } \\
\text { KR269766 }\end{array}$ & $\begin{array}{l}\text { MK168685 100\% with } \\
\text { KR269766 }\end{array}$ & $\begin{array}{l}\text { MK168669 99\% with } \\
\text { KR269766 }\end{array}$ \\
\hline LFDR4 & & $\begin{array}{l}\text { MK168713 99\% with } \\
\text { KR269766 }\end{array}$ & $\begin{array}{l}\text { MK168686100\% with } \\
\text { KR269766 }\end{array}$ & $\begin{array}{l}\text { MK168670 99\% with } \\
\text { KR269766 }\end{array}$ \\
\hline$\overline{\text { LFZE1 }}$ & Tylodelphys sp. & MK168714 no homology & $\begin{array}{l}\text { MK168689 99\% with } \\
\text { KY462834 }\end{array}$ & $\begin{array}{l}\text { MK168673 99\% with } \\
\text { Tylodelphys clavata } \\
\text { JQ665459 }\end{array}$ \\
\hline LFZE2 & & MK168715 no homology & $\begin{array}{l}\text { MK168690 99\% with } \\
\text { KY462834 }\end{array}$ & $\begin{array}{l}\text { MK168674 99\% with } \\
\text { Tylodelphys clavata } \\
\text { JQ665459 }\end{array}$ \\
\hline LFZE3 & & MK168716 no homology & $\begin{array}{l}\text { MK16869199\% with } \\
\text { KY462834 }\end{array}$ & $\begin{array}{l}\text { MK168675 99\% with } \\
\text { Tylodelphys clavata } \\
\text { JQ665459 }\end{array}$ \\
\hline LFJO1 & Australapatemon sp. & $\begin{array}{l}\text { MK168709 99\% with } \\
\text { Australapatemon burti } \\
\text { MF398342 }\end{array}$ & $\begin{array}{l}\text { MK168687 98\% with } \\
\text { Australapatemon burti } \\
\text { JX9777785 }\end{array}$ & $\begin{array}{l}\text { MK168671 99\% with } \\
\text { KY570947 }\end{array}$ \\
\hline LFJO2 & & $\begin{array}{l}\text { MK168710 99\% with } \\
\text { Australapatemon burti } \\
\text { MF398342 }\end{array}$ & $\begin{array}{l}\text { MK168688 98\% with } \\
\text { Australapatemon burti } \\
\text { JX9777785 }\end{array}$ & $\begin{array}{l}\text { MK168672 99\% with } \\
\text { KY570946 }\end{array}$ \\
\hline LFDC42 & & $\begin{array}{l}\text { MK168703 99\% with } \\
\text { Australapatemon burti } \\
\text { MF398342 }\end{array}$ & & $\begin{array}{l}\text { MK168666 99\% with } \\
\text { KY570947 }\end{array}$ \\
\hline LFDC48 & & $\begin{array}{l}\text { MK168724 99\% with } \\
\text { Australapatemon burti } \\
\text { MF398342 }\end{array}$ & & $\begin{array}{l}\text { MK168667 99\% with } \\
\text { KY570947 }\end{array}$ \\
\hline LFDC86 & & $\begin{array}{l}\text { MK168735 99\% with } \\
\text { Australapatemon burti } \\
\text { MF398342 }\end{array}$ & & $\begin{array}{l}\text { MK500246 99\% with } \\
\text { KY570947 }\end{array}$ \\
\hline LFDC43 & Cotylurus sp. & $\begin{array}{l}\text { MK168704 99\% with } \\
\text { Cotylurus cornutus } \\
\text { KY513182 }\end{array}$ & & \\
\hline LFDC88 & & $\begin{array}{l}\text { MK168726 99\% with } \\
\text { Cotylurus cornutus } \\
\text { KY513182 }\end{array}$ & & \\
\hline LFDC89 & & $\begin{array}{l}\text { MK168736 99\% with } \\
\text { Cotylurus cornutus } \\
\text { KY51318 }\end{array}$ & & \\
\hline LFDC90 & & $\begin{array}{l}\text { MK168738 99\% with } \\
\text { Cotylurus cornutus } \\
\text { KY513182 }\end{array}$ & & \\
\hline LFDC91 & & $\begin{array}{l}\text { MK168739 99\% with } \\
\text { Cotylurus cornutus } \\
\text { KY513182 }\end{array}$ & & \\
\hline LFDC83 & Posthodiplostomum sp. & MK168734 no homology & & $\begin{array}{r}\text { MK500245 99\% with } \\
\text { Posthodiplostomum } \\
\text { cuticola MF171001 }\end{array}$ \\
\hline LFDC96 & Parastrigea sp. & $\begin{array}{l}\text { MK168740 98\% with } \\
\text { Apharyngostrigea cornu } \\
\text { MF398345 }\end{array}$ & & $\begin{array}{l}\text { MK500247 99\% with } \\
\text { Parastrigea robusta } \\
\text { MF537208 }\end{array}$ \\
\hline
\end{tabular}


Table 2. (Continued)

Cercarial reference Cercarial identification Genbank accession numbers obtained in the present study (in red) and homologies with those extracted from Genbank (in black). In grey, no molecular identification.

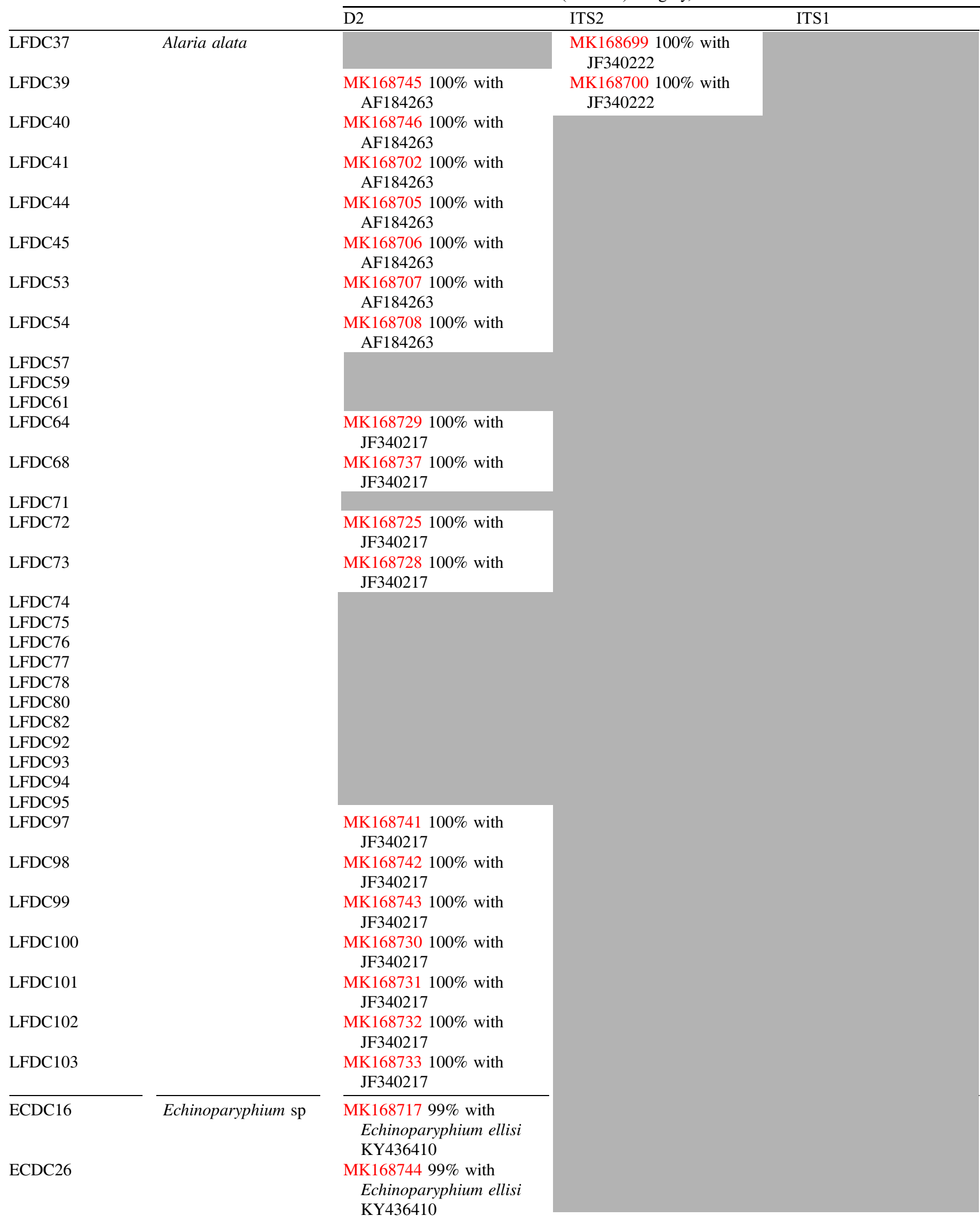


Table 2. (Continued)

\begin{tabular}{|c|c|c|c|c|}
\hline \multirow[t]{2}{*}{ Cercarial reference } & \multirow[t]{2}{*}{ Cercarial identification } & \multicolumn{3}{|c|}{$\begin{array}{l}\text { Genbank accession numbers obtained in the present study (in red) and homologies with } \\
\text { those extracted from Genbank (in black). In grey, no molecular identification. }\end{array}$} \\
\hline & & $\overline{\mathrm{D} 2}$ & ITS2 & ITS1 \\
\hline ECJO1 & Echinostoma revolutum & $\begin{array}{l}\text { MK168720 } 100 \% \text { with } \\
\text { KP065596 }\end{array}$ & $\begin{array}{l}\text { MK168694 99\% with } \\
\text { AY68930 }\end{array}$ & $\begin{array}{l}\text { MK168678 99\% with } \\
\text { KM20150 }\end{array}$ \\
\hline ECJO2 & & $\begin{array}{l}\text { MK168727 } 100 \% \text { with } \\
\text { KP065596 }\end{array}$ & $\begin{array}{l}\text { MK168695 99\% with } \\
\text { AY68930 }\end{array}$ & $\begin{array}{l}\text { MK168679 99\% with } \\
\text { KM20150 }\end{array}$ \\
\hline ECJO3 & & $\begin{array}{l}\text { MK168721 100\% with } \\
\text { KP065596 }\end{array}$ & $\begin{array}{l}\text { MK168696 99\% with } \\
\text { AY68930 }\end{array}$ & $\begin{array}{l}\text { MK168680 99\% with } \\
\text { KM20150 }\end{array}$ \\
\hline ECDR1 & Petasiger phalacrocoracis & $\begin{array}{l}\text { MK168718 } 100 \% \text { with } \\
\text { JQ425593 }\end{array}$ & $\begin{array}{l}\text { MK168692 } 100 \% \text { with } \\
\text { JQ425593 }\end{array}$ & $\begin{array}{l}\text { MK168676 99\% with } \\
\text { KJ720683 }\end{array}$ \\
\hline ECDR2 & & $\begin{array}{l}\text { MK168719 100\% with } \\
\text { JQ425593 }\end{array}$ & $\begin{array}{l}\text { MK168693 100\% with } \\
\text { JQ425593 }\end{array}$ & $\begin{array}{l}\text { MK168677 99\% with } \\
\text { KJ720683 }\end{array}$ \\
\hline XIDR2 & Plagiorchis sp & $\begin{array}{l}\text { MK168722 99\% with } \\
\text { KF533392 }\end{array}$ & MK168697 no homology & $\begin{array}{l}\text { MK168681 99\% with } \\
\text { JX522536 }\end{array}$ \\
\hline XIDR3 & & $\begin{array}{l}\text { MK168723 99\% with } \\
\text { KF533392 }\end{array}$ & MK168698 no homology & $\begin{array}{l}\text { MK168682 100\% with } \\
\text { JX522536 }\end{array}$ \\
\hline
\end{tabular}

FO: ocellated pigmented furcocercariae, LF: furcocercariae with or not eyes spots, EC: cercariae of Echinostomidae, XI: Xiphidiocercariae, DR: Der-Chantecocq lake, DC: National Domain of Chambord, ZE: Zebulle Park Chevenon, JO, Jouaignes.

Table 3. Molecular identification of snail hosts.

\begin{tabular}{|c|c|c|c|}
\hline \multirow[t]{2}{*}{ Reference snails } & \multirow[t]{2}{*}{ Identification of snails } & \multicolumn{2}{|c|}{$\begin{array}{l}\text { Genbank accession numbers obtained in the present study (in red) and } \\
\text { homologies with those extracted from Genbank (in black). In grey, no } \\
\text { molecular identification. }\end{array}$} \\
\hline & & $16 \mathrm{~S}$ & Cox 1 \\
\hline DRFO1 & Radix sp. & & \\
\hline DRLF1 & Lymnea stagnalis & & \\
\hline DRLF3 & Lymnea stagnalis & & \\
\hline DRLF4 & Lymnea stagnalis & & \\
\hline ZELF1 & Radix auricularia & KM168747 99\% with KP098540 & MK124575 no homology \\
\hline ZELF2 & Radix sp. & & \\
\hline ZELF3 & Radix auricularia & KM168747 99\% with KP098540 & \\
\hline JOLF1 & Stagnicola palustris & KM168749 99\% with HQ659900 & MK124565 no homology \\
\hline JOLF2 & Stagnicola palustris & KM168750 99\% with HQ659900 & MK124566 no homology \\
\hline DCLF42 & Planorbis planorbis & & MK124571 99\% with JQ776562 \\
\hline DCLF48 & Planorbis sp. & & \\
\hline DCLF86 & Planorbis planorbis & KM168751 99\% with JQ776562 & \\
\hline DCLF43 & Stagnicola palustris & KM168752 99\% with HQ659900 & MK124567 no homology \\
\hline DCLF88 & Stagnicola palustris & KM168753 99\% with HQ659900 & MK124568 no homology \\
\hline DCLF89 & Stagnicola palustris & KM168754 99\% with HQ659900 & MK124569 no homology \\
\hline DCLF90 & Stagnicola sp. & & \\
\hline DCLF91 & Stagnicola palustris & KM168755 99\% with HQ659900 & MK124570 no homology \\
\hline DCLF83 & Planorbis planorbis & KM168756 99\% with JQ776589 & MK124573 99\% with JQ776562 \\
\hline DCLF96 & Planorbis planorbis & KM168757 99\% with JQ776589 & \\
\hline DCLF37 & Planorbis sp. & & \\
\hline DCLF39 & Planorbis sp. & & \\
\hline DCLF40 & Planorbis sp. & & \\
\hline DCLF41 & Planorbis sp. & KM168758 97\% with JQ776589 & \\
\hline DCLF44 & Planorbis sp. & & \\
\hline DCLF45 & Planorbis planorbis & KM168759 99\% with JQ776588 & \\
\hline DCLF53 & Planorbis sp. & & \\
\hline DCLF54 & Planorbis planorbis & KM168760 99\% with JQ776588 & \\
\hline DCLF57 & Planorbis planorbis & KM168761 99\% with JQ776588 & \\
\hline DCLF59 & Planorbis planorbis & KM168762 99\% with JQ776588 & \\
\hline DCLF61 & Planorbis planorbis & KM168763 99\% with JQ776588 & \\
\hline DCLF64 & Planorbis planorbis & KM168764 99\% with JQ776588 & \\
\hline
\end{tabular}


Table 3. (Continued)

\begin{tabular}{|c|c|c|c|}
\hline \multirow[t]{2}{*}{ Reference snails } & \multirow[t]{2}{*}{ Identification of snails } & \multicolumn{2}{|c|}{$\begin{array}{l}\text { Genbank accession numbers obtained in the present study (in red) and } \\
\text { homologies with those extracted from Genbank (in black). In grey, no } \\
\text { molecular identification. }\end{array}$} \\
\hline & & $16 \mathrm{~S}$ & Cox1 \\
\hline $\begin{array}{l}\text { DCLF68 } \\
\text { DCLF71 }\end{array}$ & $\begin{array}{l}\text { Planorbis sp. } \\
\text { Planorbis sp. }\end{array}$ & & \\
\hline DCLF72 & Planorbis planorbis & KM168765 99\% with JQ776587 & MK124572 99\% with JQ776562 \\
\hline DCLF73 & Anisus sp. & KM168766 no homology & \\
\hline DCLF74 & Anisus sp. & KM168767 98\% with AY577477 & \\
\hline DCLF75 & Planorbis planorbis & KM168768 99\% with JQ776588 & \\
\hline DCLF76 & Planorbis sp. & & \\
\hline DCLF77 & Anisus sp. & KM168769 no homology & \\
\hline DCLF78 & Planorbis planorbis & KM168770 99\% with JQ776587 & \\
\hline DCLF80 & Planorbis sp. & KM168771 98\% with JQ776589 & \\
\hline DCLF82 & Planorbis planorbis & KM168772 99\% with AY577476 & \\
\hline DCLF92 & Planorbis planorbis & KM168773 99\% with JQ776587 & \\
\hline DCLF93 & Planorbis sp. & & \\
\hline DCLF94 & Planorbis sp. & & \\
\hline DCLF95 & Planorbis sp. & & \\
\hline DCLF97 & Planorbis sp. & & \\
\hline DCLF98 & Planorbis sp. & & \\
\hline DCLF99 & Planorbis sp. & & \\
\hline DCLF100 & Planorbis sp. & & \\
\hline DCLF101 & Planorbis sp. & & \\
\hline DCLF102 & Planorbis sp. & & \\
\hline DCLF103 & Planorbis planorbis & KM168774 99\% with JQ776587 & \\
\hline DCEC16 & Planorbis planorbis & KM168775 99\% with JQ776589 & \\
\hline DCEC26 & Planorbis planorbis & KM168776 99\% with JQ776587 & \\
\hline JOEC1 & Stagnicola sp. & & \\
\hline JOEC2 & Stagnicola palustris & KM168777 99\% with HQ659900 & \\
\hline JOEC3 & Stagnicola palustris & KM168778 99\% with HQ659900 & \\
\hline DREC1 & Radix balthica & KM168779 99\% with KP098541 & MK124574 no homology \\
\hline DREC2 & Radix sp. & & \\
\hline DRXI2 & Lymnea stagnalis & & \\
\hline DRXI3 & Lymnea stagnalis & & \\
\hline
\end{tabular}

FO: ocellated pigmented furcocercariae, LF: furcocercariae with or not eyes spots, EC: cercariae of Echinostomidae, XI: Xiphidiocercariae, DR: Der-Chantecocq lake, DC: National Domain of Chambord, ZE: Zebulle Park Chevenon, JO: Jouaignes.

there was no false identification for the 183 spectra preserved in ethanol attaining the 1.7 cut-off.

In a second round, we analyzed the effect of exposure time to ethanol on collected samples and freshly emitted samples. Among the 1074 spectra (including the 561 previously described), 287 (26.72\%) reached the 1.7 LSV cut-off (all of them were concordant with molecular identification). There was no clear tendency of LSV to decrease as a function of preservation time. When comparing spectra obtained from fresh cercariae versus those obtained with cercariae fixed or conserved in ethanol, we mainly observed a degradation of peak intensity resulting in a lower signal-to-noise ratio. Representative spectra are shown in Figure 4.

\section{Discussion}

We propose MALDI-TOF MS as a rapid and reliable identification system for cercariae.

This approach is easier to implement than morphological identification. Indeed, according to Gaillot et al. [13], identification of morphological differences between species of Trematoda at the cercaria stage relies on structures that can only be found in fresh cercariae (after contact with urine for the excretory system or carmine-borax staining). For cercariae with forked tails and with colorless eye spots, the morphological feature used is the position of the penetration glands: preacetabular (Tylodelphys sp., Cotylurus sp.) or postacetabular (Diplostomum sp. and Australapatemon sp.). For the last two taxa, the size of the glands and the body spinose are the morphological features used for diagnosis when emitted by Lymnaea stagnalis [10]. With regard to the cercaria emitted by planorbid snails [11], as for example those of Alaria alata, Parastrigea sp., and Australapatemon sp., other morphological features (number of rows of spines, size of spines around suckers, flame-cell formula and body spinose or not) are used to distinguish these genera. To avoid the use of several identification keys, it would be beneficial to have only one approach to the cercariae, regardless of the snail and its living environment.

Identification by molecular biology remains an expensive technique that requires trained staff as well as expertise in processing and interpreting the results. 

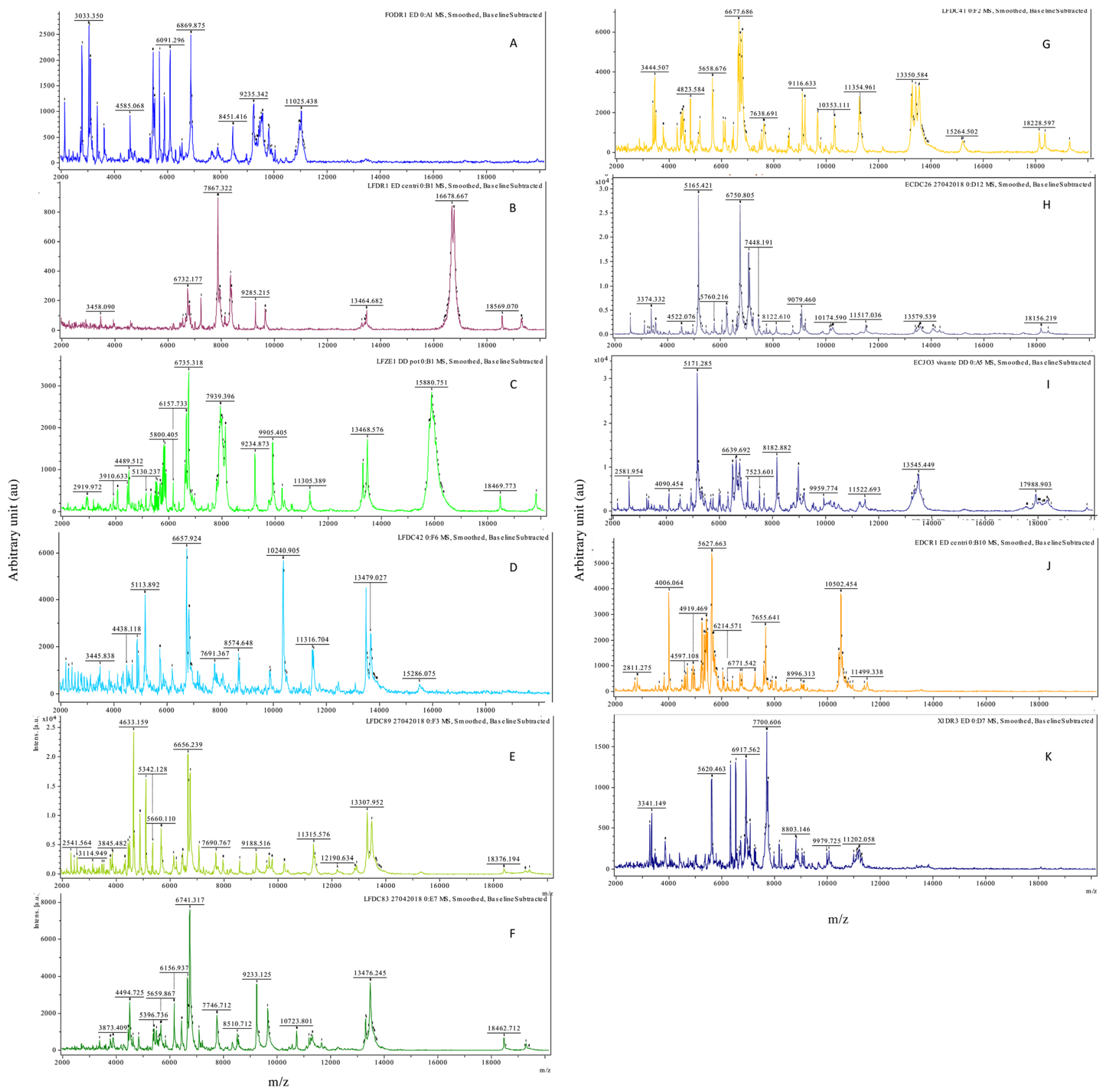

$\mathrm{m} / \mathrm{z}$

Figure 1. Representative MALDI-TOF spectra of cercariae obtained using a simple direct-deposit protocol. Flex Analysis software, smoothed spectra with baseline substracted A: Trichobilharzia anseri (FODR1) B: Diplostomum pseudospathaceum (LFDR1) C: Tylodelphys sp. (LFZE1) D: Australapatemon sp. (LFDC42) E: Cotylurus sp. (LFDC89) F: Posthodiplostomum sp. (LFDC83) G: Alaria alata (LFDC 41) H: Echinoparyphium sp. (ECDC26) I: Echinostoma revolutum (ECJO3) J: Petasiger phalacrocoracis (ECDR1) K: Plagiorchis sp. (XIDR3)

In our study, we demonstrated the ability of MALDI-TOF MS to reliably identify cercariae using a simple protocol. This direct deposit protocol is particularly time-saving compared to morphological and molecular methods. It allows high-throughput identification with more than one hundred specimens processed per day.

MALDI-TOF MS technology is nowadays increasingly accessible to clinical and research laboratories. This approach is also cost-effective as only a small number of reagents are needed. The cost of identifying bacteria using a direct deposit protocol on reusable targets was evaluated at $€ 0.12$ per well [13].

We found good discriminatory power when differentiating between the studied groups. This encouraging analytical performance needs to be confirmed on a larger number of taxa, including closely related species such as Diplostomum pseudospathaceum, D. spathaceum and D. phoxini.

According to Bruker's recommendations, LSVs under 1.7 were considered invalid identification. LSVs between 1.7 and 2.0 were considered valid at the genus level, and LSVs higher 

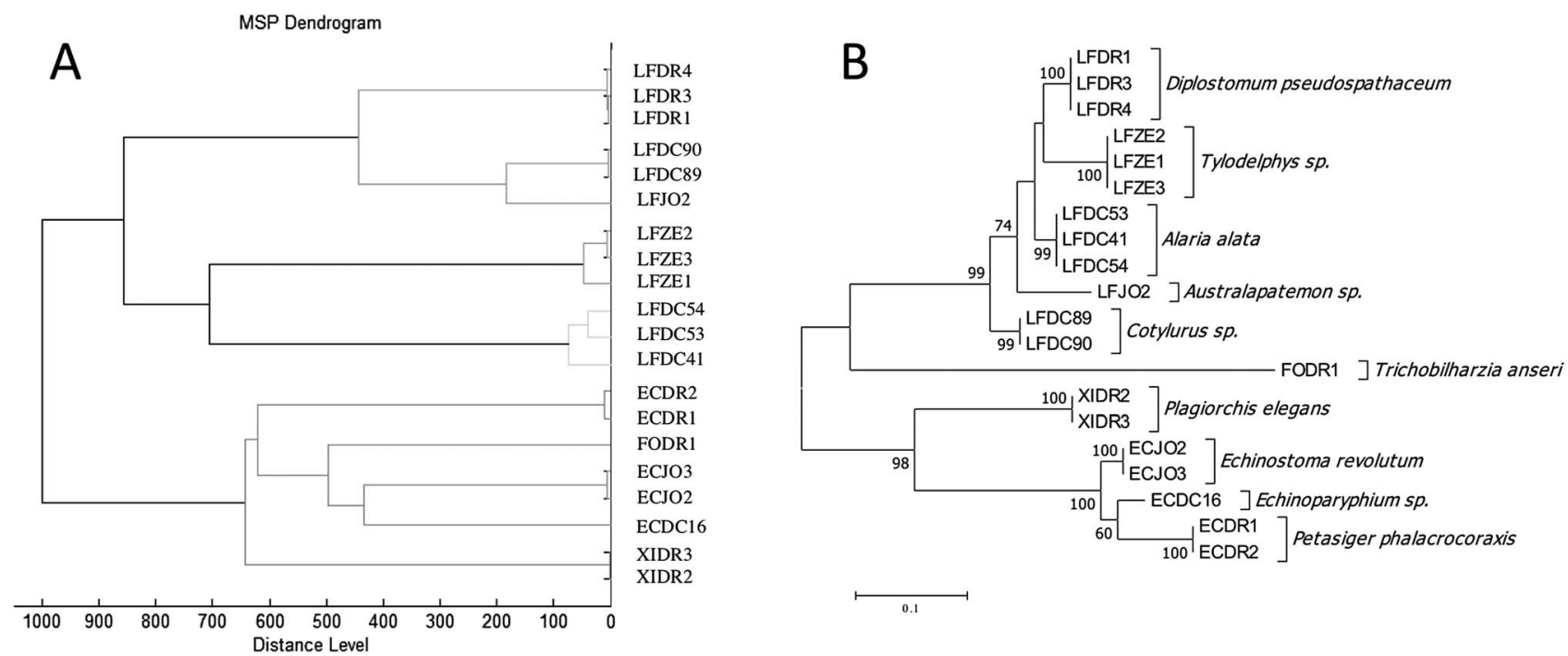

Figure 2. Panel A: Hierarchical clustering dendrogram of MALDI-TOF MSP, using the correlation distance measure and Ward algorithm. All the MSPs were included in the final database. Panel B: Maximum likelihood tree of the D2 domain of the cercariae strains present in the MALDI-TOF spectral database.

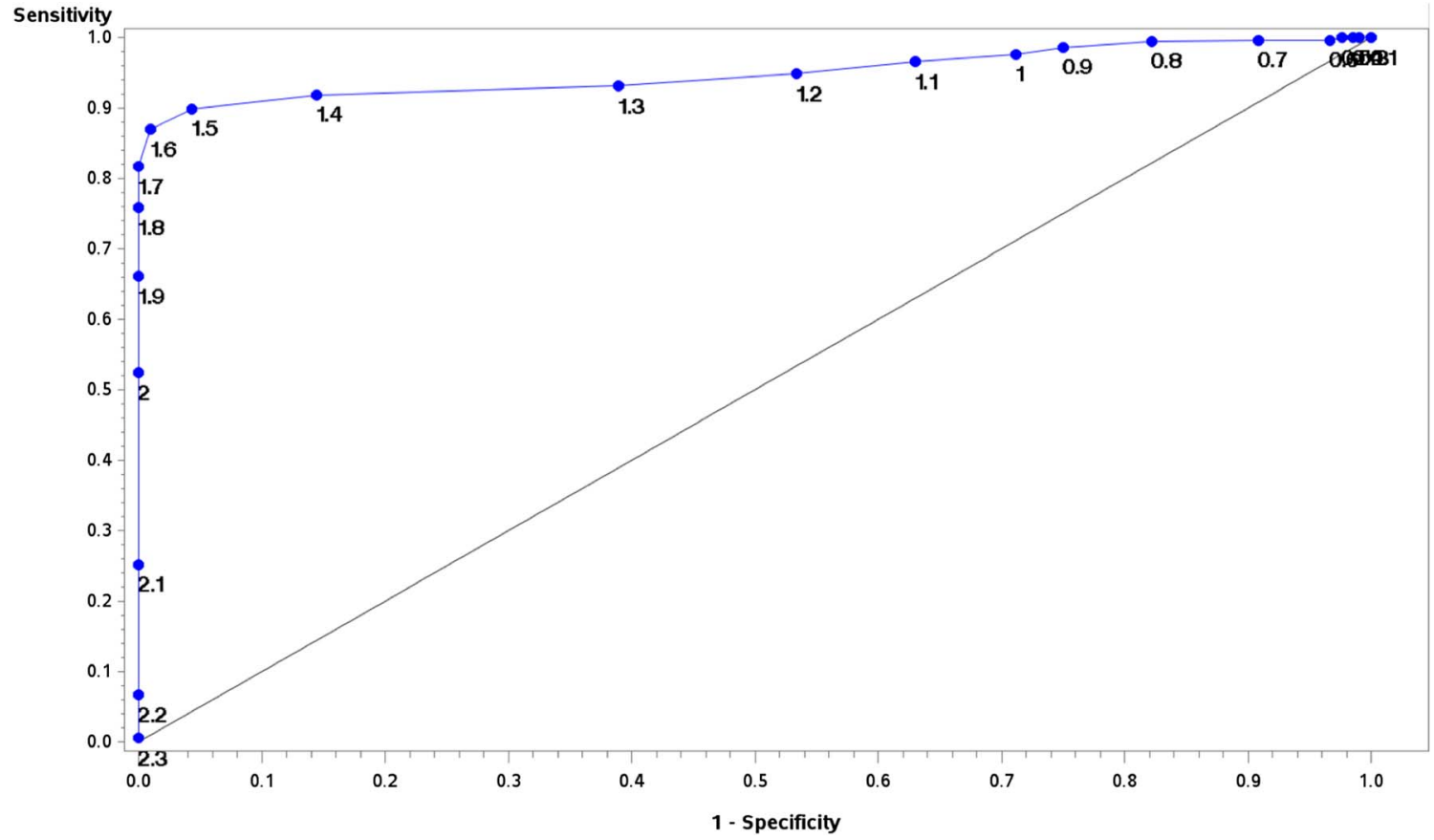

Figure 3. ROC curve for determination of the optimal LSV cut-off. Logistic regression model based on identification prediction using the final version of the MALDI-TOF cercariae database compared to molecular identification.

than 2.0 were considered reliable identification at the species level. In our study, using an LSV cut-off of 2.0 for identification at the species level was highly specific, but resulted in a high proportion of unidentified spectra. Lowering the cut-off to 1.7 allowed for the identification of a higher number of specimens with similar specificity. This cut-off value has already been proposed for species-level identification of filamentous fungi $[4,29]$. Further studies are needed for the validation of this cut-off on upgraded spectral databases with a higher number of taxa.
In our study, we observed a high proportion of "flat-line" and low-quality spectra. These can be explained by the heterogeneity of the cercariae deposited in the MALDI-TOF target. In our experience, four deposits per sample is a good compromise between deposit and acquisition time, and generally enables identification of the sample with at least an LSV $>1.7$ on one well.

We did not note any influence of the species of emitting mollusc. This allowed us to confirm the circulation of Alaria alata in Planorbis as well as in Anisus. We also have found 

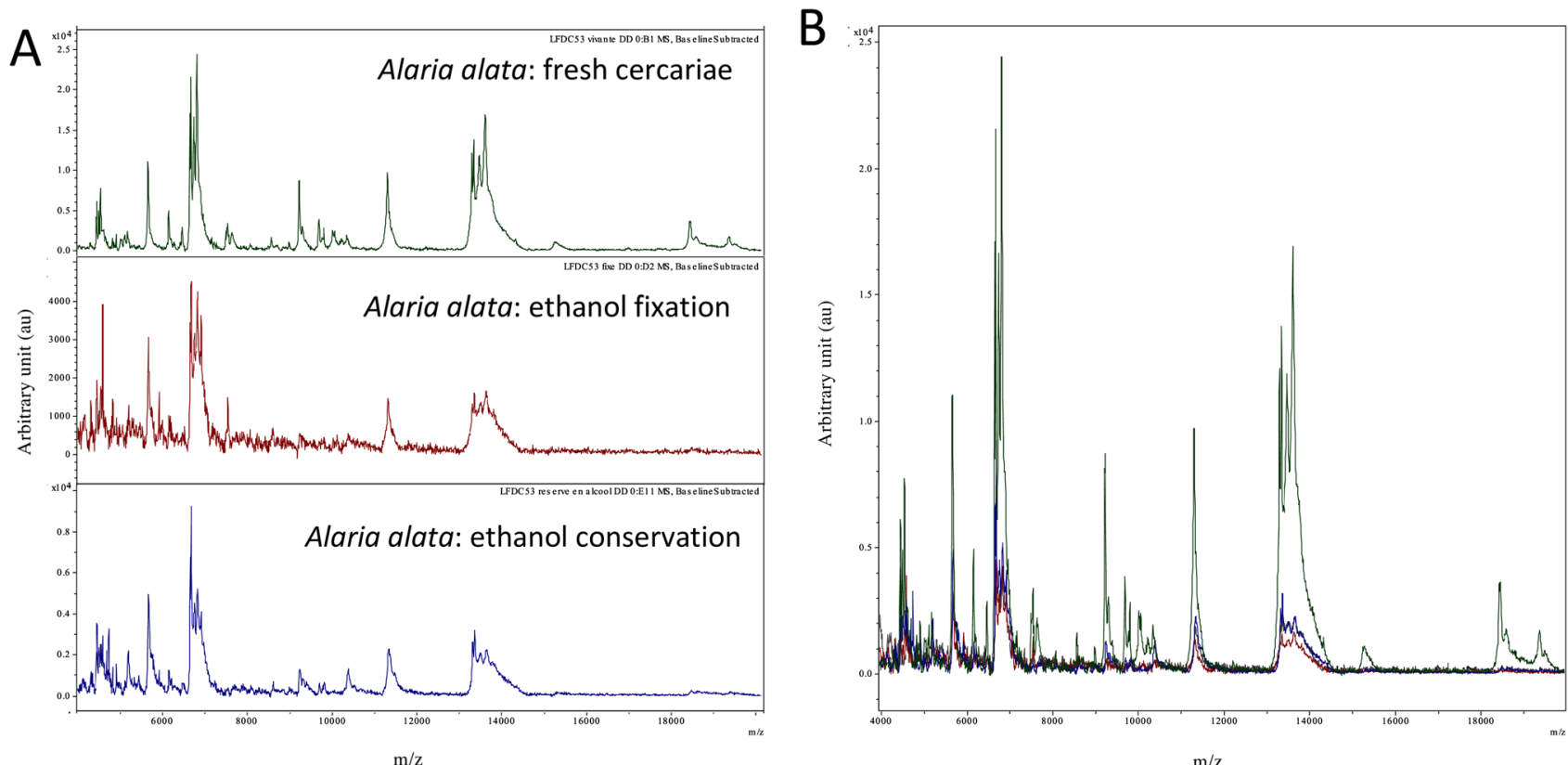

Figure 4. Panel A: Representative MALDI-TOF spectra of the same specimen (LFDC53) under the following conditions: fresh cercariae, ethanol fixation, and ethanol conservation (12 months). Panel B: Superposition of panel A spectra.

the same species, Australapatemon sp., in two different locations on two different species of snails. There was also no spectral difference in the same species at different times of study, or between two emissions of the same cercarial species by a same mollusc. These results appear to show that the signal measured by MALDI-TOF mass spectrometry is specific to the studied cercariae and not artefacts of the mollusc or the living environment. MALDI-TOF MS therefore seems to be a reproducible method for cercariae identification. In this study, we observed emission of only a single type of cercariae by each positive snail. Co-infection with two trematodes in the same snail is rarely observed in natural conditions and usually concerns two morphotypes of associated cercariae (e.g., forked tail/ Echinostomatidae; Echinostomatidae/xiphidiocercariae; furcocercariae with eye spots/xiphidiocercariae), as shown in experimental conditions on competitive antagonism [12, 25]. Even though two cercariae can be emitted at the same time by a single snail, no cases of associations with the same morphotype of cercariae have been reported.

Fixation of cercariae and their storage in ethanol leads to degradation of spectral intensity, resulting in a high proportion of unidentified spectra. This raises a problem for the retrospective study of collections stored in ethanol. The study of other storage methods for the biological material, such as freezing at different temperatures and other fixatives, seems important for the development of this technique.

We constituted for this study an MSP database with a limited number of Trematoda species. It must be improved by inclusion of new species to cover the broad range of Trematoda involved in veterinary or human medicine. The database would also be improved by increasing the number of strains for a given taxa [30].

Our study highlights the huge potential of MALDI-TOF for large epidemiological surveys of Trematoda.
This technique could thus be applied to the study of human schistosomiasis, including the detection of hybrids [3, 8, 24], allowing for rapid and precise identification of the cercariae obtained during large snail collection campaigns. It would be of particular interest in areas of mixed circulation. Another field of application is the environmental survey of flukes of interest in human and veterinary medicine.

\section{Conclusion}

MALDI-TOF MS is a promising technique for cercariae identification at the species level. It has great discriminatory power using a rapid and easy preparation protocol. The implementation of a spectral database, gathering a large number of species, is one of our objectives for use in routine identification.

Acknowledgements. Financial support for this study was provided through a research agreement between Hubert Ferté and ONCFS (French game and wildlife agency including the SAGIR network), and partially by the ARS (regional health agency) of Burgundy. We would like to thank the technical staff of the national domain of Chambord (Etienne Guillaumat, Philippe Hubert, Pascal Blondeau), the technical staff of the national reserve of Der-Chantecocq lake (Yves Maupoix), and Mrs Leroux for their hospitality during snail collection. We also thank Mireille Cousinat and Denis Augot for their technical assistance, as well as Matthieu Kaltenbach for proofreading this manuscript.

\section{Conflict of interest}

None of the authors of this manuscript have a commercial or other interest that might represent a conflict (e.g., pharmaceutical stock ownership, consultancy). 


\section{References}

1. Avila CC, Almeida FG, Palmisano G. 2016. Direct identification of trypanosomatids by matrix-assisted laser desorption ionization-time of flight mass spectrometry (DIT MALDI-TOF MS). Journal of Mass Spectrometry, 51(8), 549-557.

2. Blasco-Costa I, Locke SA. 2017. Life history, systematics and evolution of the Diplostomoidea Poirier, 1886: Progress, promises and challenges emerging from molecular studies. Advances in Parasitology, 98, 167-225.

3. Boissier J, Grech-Angelini S, Webster BL, Allienne J-F, Huyse T, Mas-Coma S, Toulza E, Barré-Cardi H, Rollinson D, KincaidSmith J, Oleaga A, Galinier R, Foata J, Rognon A, Berry A, Mouahid G, Henneron R, Moné H, Noel H, Mitta G. 2016. Outbreak of urogenital schistosomiasis in Corsica (France): an epidemiological case study. Lancet Infectious Diseases, 16(8), 971-979.

4. Cassagne C, Ranque S, Normand A-C, Fourquet P, Thiebault S, Planard C, Hendrickx M, Piarroux R. 2011. Mould routine identification in the clinical laboratory by Matrix-Assisted Laser Desorption Ionization Time-Of-Flight Mass Spectrometry. PLoS One, 6(12), e28425.

5. Clark AE, Kaleta EJ, Arora A, Wolk DM. 2013. Matrix-assisted laser desorption ionization-time of flight mass spectrometry: A fundamental shift in the routine practice of clinical microbiology. Clinical Microbiology Reviews, 26(3), 547-603.

6. Colley DG, Bustinduy AL, Secor WE, King CH. 2014. Human schistosomiasis. Lancet, 383(9936), 2253-2264.

7. Combes C, Albaret J-L, Arvy L, Bartoli P, Bayssade-Dufour C, Deblock S, Durette-Desset M-C, Gabrion C, Jourdane J, Lambert A, Léger N, Maillard C, Matricon M, Nassi H, Prévot G, Richard J, Théron A. 1980. World atlas of cercariae. Atlas mondial des cercaires. Vol. 115. Paris, France: Mémoires du Muséum National d'Histoire Naturelle, 1-236.

8. Depaquit J, Akhoundi M, Haouchine D, Mantelet S, Izri A. 2019. No limit in interspecific hybridization in schistosomes: observation from a case report. Parasite, 26, 10.

9. Dvorák J, Vanácová S, Hampl V, Flegr J, Horák P. 2002. Comparison of European Trichobilharzia species based on ITS1 and ITS2 sequences. Parasitology, 124(Pt 3), 307-313.

10. Faltýnková A, Našincová V, Kablásková L. 2007. Larval trematodes (Digenea) of the great pond snail, Lymnaea stagnalis (L.), (Gastropoda, Pulmonata) in Central Europe: a survey of species and key to their identification. Parasite, 14(1), 39-51.

11. Faltýnková A, Našincová V, Kablásková L. 2008. Larval trematodes (Digenea) of planorbid snails (Gastropoda: Pulmonata) in Central Europe: a survey of species and key to their identification. Systematic Parasitology, 69(3), 155-178.

12. Frandsen F. 1976. The suppression, by Helisoma duryi, of the cercarial production of Schistosoma mansoni-infected Biomphalaria pfeifferi. Bulletin of The World Health Organization, 53(4), 385-390.

13. Gaillot O, Blondiaux N, Loïez C, Wallet F, Lemaitre N, Herwegh S, Courcol RJ. 2011. Cost-effectiveness of switch to matrix-assisted laser desorption ionization-time of flight mass spectrometry for routine bacterial identification. Journal of Clinical Microbiology, 49(12), 4412-4412.

14. Georgieva S, Soldánová M, Pérez-del-Olmo A, Dangel DR, Sitko J, Sures B, Kostadinova A. 2013. Molecular prospecting for European Diplostomum (Digenea: Diplostomidae) reveals cryptic diversity. International Journal for Parasitology, 43(1), 57-72.

15. Glöer P, Meier-Brook C. 2002. Süßwassergastropoden Nordund Mitteleuropas Die Tierwelt Deutschlands. Vol. 73. Harxheim, Germany: Conchbooks. p. 327.
16. Hall TA. 1999. BioEdit: a user-friendly biological sequence alignment editor and analysis program for Windows 95/98/NT. Nucleic Acids Symposium Series, 41, 95-98.

17. Horák P, Kolářová L, Mikeš L. 2014. Schistosomatoidea and Diplostomoidea, inDigenetic Trematodes. New York, NY: Springer. p. 331-364.

18. Huang Y, Li W, Liu K, Xiong C, Cao P, Tao J. 2016. New detection method in experimental mice for schistosomiasis: ClinProTool and matrix-assisted laser desorption/ionization time-of-flight mass spectrometry. Parasitology Research, 115 (11), 1-9.

19. Jørgensen A, Kristensen TK, Stothard JR. 2004. An investigation of the "Ancyloplanorbidae" (Gastropoda, Pulmonata, Hygrophila): preliminary evidence from DNA sequence data. Molecular Phylogenetics and Evolution, 32(3), 778-787.

20. Jouet D, Skírnisson K, Kolářová L, Ferté H. 2010. Molecular diversity of Trichobilharzia franki in two intermediate hosts (Radix auricularia and Radix peregra): a complex of species. Infection, Genetics and Evolution, 10(8), 1218-1227.

21. Kumar S, Stecher G, Tamura K. 2016. MEGA7: molecular evolutionary genetics analysis version 7.0 for bigger datasets. Molecular Biology and Evolution, 33(7), 1870-1874.

22. Lachaud L, Fernández-Arévalo A, Normand A-C, Lami P, Nabet C, Donnadieu JL, Piarroux M, Djenad F, Cassagne C, Ravel C, Tebar S, Llovet T, Blanchet D, Demar M, Harrat Z, Aoun K, Bastien P, Muñoz C, Gállego M, Piarroux R. 2017. Identification of Leishmania by Matrix-Assisted Laser Desorption Ionization-Time of Flight (MALDI-TOF) Mass Spectrometry using a free web-based application and a dedicated mass-spectral library. Journal of Clinical Microbiology, 55(10), 2924-2933.

23. Laroche M, Almeras L, Pecchi E, Bechah Y, Raoult D, Viola A, Parola P. 2016. MALDI-TOF MS as an innovative tool for detection of Plasmodium parasites in Anopheles mosquitoes. Malaria Journal, 16(1), 1-10.

24. Le Govic Y, Kincaid-Smith J, Allienne JF, Rey O, de Gentile L, Boissier J. 2019. Schistosoma haematobium-Schistosoma mansoni hybrid parasite in migrant boy, France, 2017. Emerging Infectious Diseases, 25(2), 365-367.

25. Lie JK. 1966. Antagonistic Interaction between Schistosoma mansoni sporocysts and echinostome rediae in the snail Australorbis glabratus. Nature, 211(5054), 1213-1215.

26. Mas-Coma S, Valero MA, Bargues MD. 2014. Fascioliasis. Advances in Experimental Medicine and Biology, 766(Chapter 4), 77-114.

27. Mayer-Scholl A, Murugaiyan J, Neumann J, Bahn P, Reckinger S, Nöckler K. 2016. Rapid identification of the foodborne pathogen Trichinella spp. by Matrix-Assisted Laser Desorption/Ionization Mass Spectrometry. PLoS One, 11(3), e0152062-10.

28. Mollaret I, Jamieson BGM, Adlard RD, Hugall A, Lecointre G, Chombard C, Justine J-L. 1997. Phylogenetic analysis of the Monogenea and their relationships with Digenea and Eucestoda inferred from 28S rDNA sequences. Molecular and Biochemical Parasitology, 90(2), 433-438.

29. Normand A-C, Cassagne C, Gautier M, Becker P, Ranque S, Hendrickx M, Piarroux R. 2017. Decision criteria for MALDITOF MS-based identification of filamentous fungi using commercial and in-house reference databases. BMC Microbiology, 17(1), 1-17.

30. Normand A-C, Cassagne C, Ranque S, L'Ollivier C, Fourquet P, Roesems S, Hendrickx M, Piarroux R. 2012. Assessment of various parameters to improve MALDI-TOF MS reference spectra libraries constructed for the routine identification of filamentous fungi. BMC Microbiology, 13, 76-76. 
31. Patel R. 2014. MALDI-TOF MS: a new laboratory option for the diagnosis of clinical infections. Clinical Chemistry, 61(1), $1-5$.

32. Portier J, Jouet D, Vallée I, Ferté H. 2012. Detection of Planorbis planorbis and Anisus vortex as first intermediate hosts of Alaria alata (Goeze, 1792) in natural conditions in France: molecular evidence. Veterinary Parasitology, 190(1-2), $151-158$
33. Poulin R, Lefebvre F. 2005. Life history constraints on the evolution of abbreviated life cycles in parasitic trematodes. Journal of Helminthology, 79(1), 47-53.

34. Rahi P, Prakash O, Shouche YS. 2016. Matrix-Assisted Laser Desorption/Ionization Time-of-Flight Mass-Spectrometry (MALDI-TOF MS) based microbial identifications: challenges and scopes for microbial ecologists. Frontiers in Microbiology, $7(4), 1359$.

Cite this article as: Huguenin A, Depaquit J, Villena I \& Ferté H. 2019. MALDI-TOF mass spectrometry: a new tool for rapid identification of cercariae (Trematoda, Digenea). Parasite 26, 11.

\section{O PARASTE}

An international open-access, peer-reviewed, online journal publishing high quality papers on all aspects of human and animal parasitology

Reviews, articles and short notes may be submitted. Fields include, but are not limited to: general, medical and veterinary parasitology; morphology, including ultrastructure; parasite systematics, including entomology, acarology, helminthology and protistology, and molecular analyses; molecular biology and biochemistry; immunology of parasitic diseases; host-parasite relationships; ecology and life history of parasites; epidemiology; therapeutics; new diagnostic tools.

All papers in Parasite are published in English. Manuscripts should have a broad interest and must not have been published or submitted elsewhere. No limit is imposed on the length of manuscripts.

Parasite (open-access) continues Parasite (print and online editions, 1994-2012) and Annales de Parasitologie Humaine et Comparée (1923-1993) and is the official journal of the Société Française de Parasitologie. 